\title{
Cardiac MR detects the progression of impaired myocardial perfusion reserve in a mouse model of obesity-related cardiomyopathy
}

\author{
Nivedita K Naresh ${ }^{1 *}$, Joshua T Butcher ${ }^{2,3}$, Xiao Chen ${ }^{1}$, Brian H Annex ${ }^{4}$, Brant E Isakson ${ }^{2,3}$, Frederick H Epstein ${ }^{1,5}$ \\ From 18th Annual SCMR Scientific Sessions \\ Nice, France. 4-7 February 2015
}

\section{Background}

Obesity has become increasing prevalent in western society and is associated with increased risk of heart failure [1]. Increased body weight is independently associated with impaired myocardial perfusion reserve (MPR), even in the absence of obstructive coronary artery disease [2]. Mouse models can elucidate molecular mechanisms that underlie cardiovascular disease. In this study, we used in vivo cardiac MRI in a mouse model of diet-induced obesity to establish the time course of MPR and we further used ex vivo histological and vascular reactivity studies to elucidate factors underlying the MRI results.

\section{Methods}

Six week old C57Bl/6 mice fed a high-fat diet (HFD) (n = 9) and age-matched C57Bl/6 mice fed a low-fat diet (Control) $(\mathrm{n}=9)$ were imaged at $7 \mathrm{~T}$. Imaging was performed at 6,12, 18 and 24 weeks post-diet. Mice were anesthetized with $1.25 \%$ isoflurane and maintained at 36 $\pm 1^{\circ} \mathrm{C}$ during MRI. The MRI protocol included multislice cine imaging to assess ejection fraction, left-ventricular (LV) mass, LV wall thickness, and LV volumes, and first-pass imaging at rest and with the vasodilator Regadenoson $(0.1 \mu \mathrm{g} / \mathrm{g}$ body weight $)$ to quantify MPR. At 25 weeks post-diet, blood pressure was measured non-invasively. Vascular reactivity of isolated coronary arterioles was assessed using cumulative dose responses to adenosine and acetylcholine in a sub-group of the mice. Histology of the aorta detected the presence or absence of systemic atherosclerosis, and myocardial capillary density was quantified.

'Department of Biomedical Engineering, University of Virginia, Charlottesville, VA, USA

Full list of author information is available at the end of the article

\section{Results}

HFD mice were obese relative to Control mice at 6 weeks of diet $(31.8 \pm 5.8 \mathrm{~g}$ vs. $24.5 \pm 5.2 \mathrm{~g}, \mathrm{p}<0.05)$ and their body weight progressively increased up to 24 weeks post-diet $(45.5 \pm 5.3 \mathrm{~g}$ vs. $30.6 \pm 4.4 \mathrm{~g}, \mathrm{p}<0.05)$. Figure 1 shows examples of first-pass perfusion MRI (A-B) and cine MRI (C-D) from a mouse heart. MPR in HFD mice was reduced at 18 and 24 weeks post-diet (Figure 2A, $\mathrm{p}<0.05$ vs. age-matched control). LV mass was increased in HFD mice at 18 weeks ( $<<0.05$ vs. Control) and it further increased at 24 weeks (Figure $2 \mathrm{~B}, \mathrm{p}<0.05$ vs. Control, HFD at 18 weeks). LV wall thickness was increased in HFD mice at 18 and 24 weeks post-diet ( $<0.05$ vs. age-matched Control). Vascular reactivity of the coronary arterioles in response to acetylcholine (Figure 2C) and adenosine (Figure 2D) was reduced in HFD mice ( $\mathrm{p}<0.05$ vs. Control). There were no significant differences in volume, ejection fraction, blood pressure and capillary density measurements between the two groups. Histology showed no aortic atherosclerosis in HFD or Control mice.

\section{Conclusions}

Using cardiac MR, vascular reactivity, and histological studies, we showed that C57Bl/6 mice fed a HFD for 18-24 weeks have LV hypertrophy and reduced vasodilatory capacity at stress with normal capillary density and no aortic plaque. Future studies using cardiac MR and gene-modified mice fed a HFD may shed light on key molecular mechanisms that underlie myocardial ischemia in obesity related cardiomyopathy.

\section{Funding}

This work was funded by NIH R01 EB001763. 


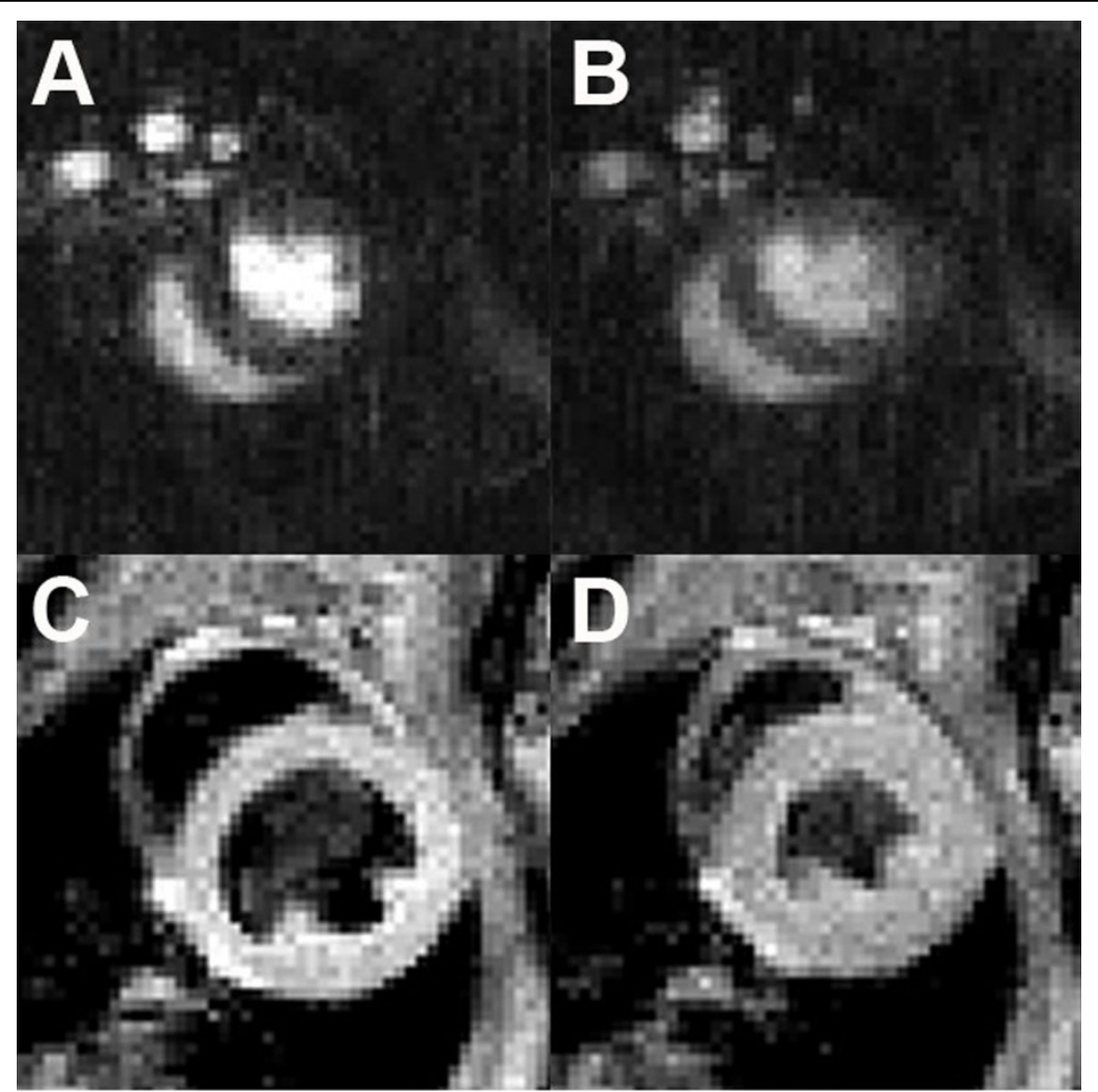

Figure 1 Example first-pass gadolinium-enhanced images (A-B), and cine images (C-D) of the mouse heart.
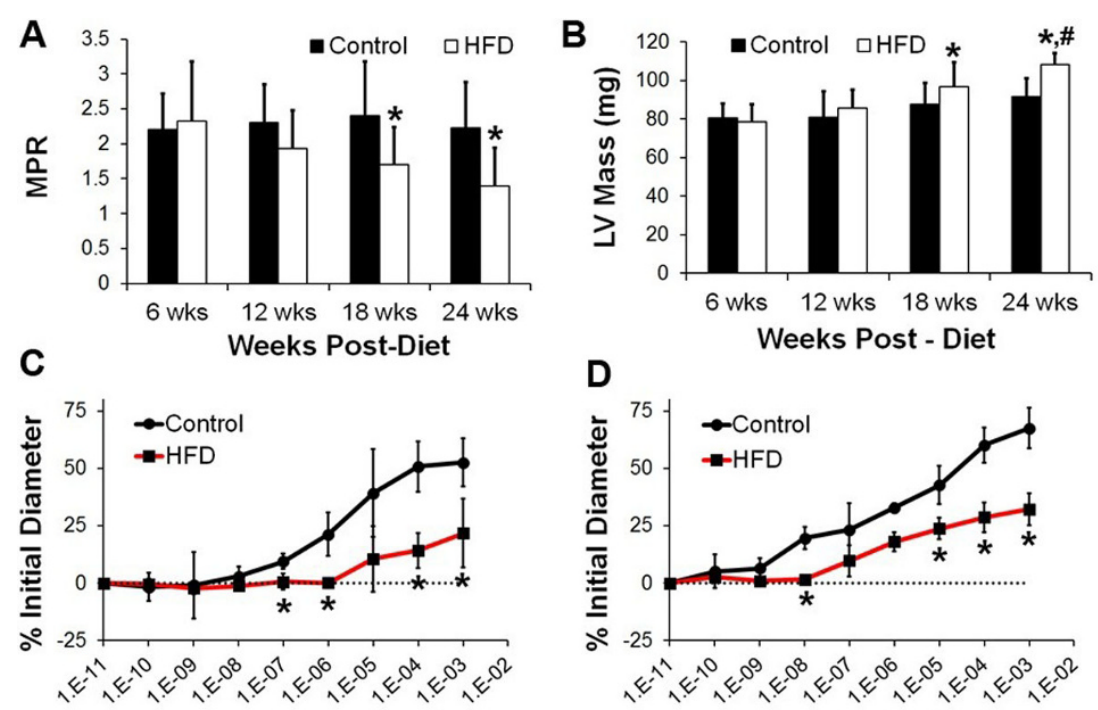

Acetylcholine (moles/L)

D

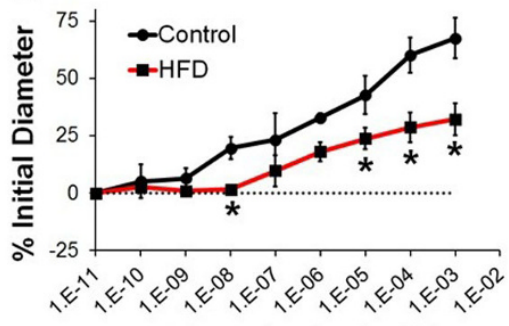

Adenosine (moles/L)

Figure 2 (A): MPR was reduced in the HFD mice as compared to the control mice at 18 and 24 weeks after diet $\left({ }^{*} p<0.05\right.$ vs. agematched control). (B): LV mass was increased in HFD mice at 18 wks after diet ( ${ }^{*} p<0.05$ vs. control) and it further increased at 24 wks after diet $\left({ }^{*} p<0.05\right.$ vs. control, $\# p<0.05$ vs. HFD at 18wks). (C): Cumulative dose responses of coronary arterioles to acetylcholine. HFD mice had reduced ability to dilate in response to acetylcholine $\left({ }^{*} p<0.05\right.$ vs. control). (D): Cumulative dose responses of coronary arterioles to adenosine. The ability to dilate the coronary arterioles in response to adenosine is significantly inhibited in the HFD mice $\left({ }^{*} p<0.05\right.$ vs. control). 


\section{Authors' details}

'Department of Biomedical Engineering, University of Virginia, Charlottesville, VA, USA. ${ }^{2}$ Robert M. Berne Cardiovascular Research Center, University of Virginia, Charlottesville, VA, USA. ${ }^{3}$ Department of Molecular Physiology and Biological Physics, University of Virginia, Charlottesville, VA, USA. ${ }^{4}$ Department of Cardiovascular Medicine, University of Virginia, Charlottesville, VA, USA.

${ }^{5}$ Department of Radiology, University of Virginia, Charlottesville, VA, USA.

Published: 3 February 2015

\section{References}

1. Kenchaiah S, et al: NEMM 2002, 347:305-313.

2. Schindler TH, et al: JACC 2006, 47(6):1188-95.

doi:10.1186/1532-429X-17-S1-P82

Cite this article as: Naresh et al:: Cardiac MR detects the progression of impaired myocardial perfusion reserve in a mouse model of obesityrelated cardiomyopathy. Journal of Cardiovascular Magnetic Resonance 2015 17(Suppl 1):P82.

\section{Submit your next manuscript to BioMed Central} and take full advantage of:

- Convenient online submission

- Thorough peer review

- No space constraints or color figure charges

- Immediate publication on acceptance

- Inclusion in PubMed, CAS, Scopus and Google Scholar

- Research which is freely available for redistribution

Submit your manuscript at www.biomedcentral.com/submit 